\title{
Relationship of Obesity with High Blood Pressure in Children and Adolescents
}

\author{
Maria Goretti Barbosa de Souza ${ }^{1}$, Ivan Romero Rivera' ${ }^{1}$, Maria Alayde Mendonça da Silva' ${ }^{1}$, Antonio Carlos \\ Camargo Carvalho ${ }^{2}$ \\ Universidade Federal de Alagoas - Faculdade de Medicina', Maceió, AL, Universidade Federal de São Paulo - Escola Paulista de Medicina², São \\ Paulo, SP - Brasil
}

\begin{abstract}
Background: Excess weight and body fat are currently recognized as the major determinants of high blood pressure in children and adolescents.

Objective: To identify the relationship between obesity - identified by waist circumference (WC), triceps skinfold thickness (TSF) and body mass index (BMI) - high blood pressure (HBP) in children and adolescents.
\end{abstract}

Methods: A cross-sectional epidemiological study based on school population in children and adolescents of both sexes, aged between 7 and 17 years, randomly selected. Protocol: a structured questionnaire; measures of weight, height, triceps skinfold thickness, waist circumference, blood pressure, diagnosis of obesity through BMI, TSF thickness and waist circumference; diagnosis of HBP. Statistical analysis: Chi-square.

Results: A total of 1,253 students (547 males, mean age $12.4 \pm 2.9$ years), were assessed. A prevalence of obesity (BMI, TSF thickness, WC) of $13.7 \%, 14,8 \%$ and $9.3 \%$ respectively were identified. HBP was identified in $7.7 \%$ of young people. There was a significant association between obesity (BMI, TSF thickness, WC) with HBP $\left({ }^{*} p<0.0001\right)$. There was a strong correlation $\left({ }^{*} p<0.01\right)$ between WC and BMI, a moderate correlation between WC and TSF thickness, WC and SBP, BMI and SBP (*p $<0.01)$; weak correlation between DBP and WC, TSF thickness and BMI, and between SBP and TSF thickness $\left({ }^{*} \mathrm{p}<0.05\right)$.

Conclusion: The significant correlation and association between HBP and excess body fat by any of the methods used establish the importance of its use in evaluating children and adolescents, aiming at preventing hypertension in this age group, suggesting, for this, the use of BMI associated to at least another anthropometric method. (Arq Bras Cardiol 2010;94(6) : 671-675)

Key words: Hypertension; obesity; child; adolescent; body mass index; waist circumference.

\section{Introduction}

There is evidence that primary high blood pressure (HBP), independent risk factor for the two most common causes of death among adults in Brazil (stroke and heart disease) ${ }^{1}$, has its roots in childhood or adolescence ${ }^{2}$, and several studies have shown that high levels of blood pressure at this age are predictors of hypertension in young adults ${ }^{3,4}$, a phenomenon known as tracking.

In its primary form (the one with no detectable cause), hypertension in childhood and adolescence seems to result from the interaction between genetic and environmental factors, such as HBP in parents ${ }^{5-7}$, salt and calorie intake $\mathrm{e}^{8,9}$ and

Mailing address: Maria Goretti Barbosa de Souza •

Cond. Aldebaram Omega Qd. F N. 04 - Jardim Petrópolis - 57080-900 -

Maceió, AL - Brazil

E-mail: mgoretti@cardiol.br, gorettib@uol.com.br

Manuscript received June 17, 2009; revised manuscript received November 15, 2009, accepted on December 23, 2009. degree of physical fitness ${ }^{10-12}$, all contributing to the emergence of other individual determinants of high blood pressure, such as heart rate ${ }^{13}$ and over-weight or body fat $\mathrm{t}^{14-17}$. In this respect, Rosa and Ribeiro ${ }^{14}$, in a review on the determinants of blood pressure in childhood and adolescence, emphasize that the central fat deposit appears to behave as an actual risk factor for hypertension while heart rate and initial levels of blood pressure at higher percentiles may be useful as hypertension markers in adulthood.

Brazilian population studies involving the pediatric population using the body mass index (BMI) as a parameter, show that the prevalence of overweight and obesity has increased in recent decades in children and adolescents ${ }^{18}$. In research conducted in 1974-1975 (Endef-IBGE), 1989 (PNSN-Inan), 1996 (POF-IBGE) and 2002-2003 (POFIBGE), it was found that in adolescents, excess body weight increased from $5.7 \%$ to $16.7 \%$, while obesity increased from $0.4 \%$ to $2.4 \%{ }^{18}$. The prevalence of overweight and obesity in adolescents (10 to 19 years) with hypertension enrolled in the Hiperdia Datasus system ranged from $41.09 \%$ to $67.33 \%{ }^{18}$, 
showing a significant association between overweight and hypertension in this group.

Some other studies conducted in Brazil with children and adolescents showed that BMI, waist circumference and skinfold thickness (parameters used for the identification of excess body fat) have a strong influence on blood pressure values ${ }^{19-22}$. Only one study failed to demonstrate such association ${ }^{23}$.

The purpose of this research is to identify, in a school population sample, the association and correlation between obesity - identified through waist circumference (WC), triceps skinfold thickness (TSF) and body mass index (BMI) - and high blood pressure (HBP) in children and adolescents.

\section{Methods}

The sample of this study is composed of a representative sample of school pupils enrolled in public elementary and secondary schools (municipal, state and federal schools), particularly from the city of Maceió, in 2001 school year, members of the study "Prevalence of cardiovascular risk factors in children and adolescents in the city of Maceió" ${ }^{24}$. This included 1,253 students of both sexes, aged 7 to 17, randomly selected from public and private schools, from primary and secondary levels in the city of Maceió ${ }^{24}$. Therefore, this sample represents the school population of primary and secondary levels, expressing their distribution by age, gender, economic status and distribution over public and private schools ${ }^{24}$.

In the age group studied, the HBP was regarded as the average (from two measurements) of systolic and/or diastolic pressure at the $95^{\text {th }}$ percentile for age and gender, adjusted to height percentile ${ }^{25-27}$. We used a Tycos sphygmomanometer, clamps with three different sizes (adult, adolescent, child) and Littman pediatric stethoscope. All measurements were performed by the same medical researcher after receiving specific training. We adopted the methodological recommendations of the Update on the Task Force Report on High Blood Pressure in Children and Adolescent, summarized by $\mathrm{Koch}^{28}$.

Anthropometric measurements (weight, height, triceps skinfold thickness and waist circumference) were performed using a Filizola-branded electronic scale, board stadiometer, Lange skinfold caliper and inelastic tape.

Weight and height were measured by team members, after specific training under the supervision of a medical researcher using the average of the two height measurements. The TSF thickness was measured at the midpoint between the acromion and olecranon on the back of the right arm by a single researcher, using the average of these three measures. WC measurement was performed by the same researcher at the midpoint between the lower portion of the last rib and the upper edge of the iliac crest, using the average of two measures.

The body mass index (BMI) on the percentile greater than or equal to 85 , identified on a population-specific table based on age was used to define obesity ${ }^{29}$. Obesity diagnosis was also performed by measuring the triceps skinfold thickness (TSF) using the parameters of Must et $\mathrm{al}^{29}$, which establish that the TSF thickness on a percentile equal to or greater than
85, identified on tables derived from the National Health and Nutrition Examination Survey I (NHANES I), identifies obese individuals. We also used waist circumference (WC) on the percentile above 75 to define central obesity, as proposed by Fernandez et $\mathrm{al}^{30}$.

For association analyses, we used the chi-square test or Fisher's exact test to establish the $5 \%$ level to reject the nullity hypothesis. The linear correlation was used in the study of the relationship between BMI, TSF, WC and blood pressure percentiles.

The research project was initially approved by the Ethics Committee of the University Hospital and later by the Ethics Committee on Research of the Federal University of Alagoas.

\section{Results}

The sample of this study consisted of 547 male students (43.7\%) and 706 females (56.3\%), aged 7 to 17 , mean ( SD) $12.4 \pm 2.9$ years.

The mean values, standard deviation, median, minimum and maximum for continuous variables (age, body mass index, triceps skinfold thickness, waist circumference, systolic and diastolic blood pressure) are shown in Table 1.

HBP identified as the average (of two measures) of systolic and/or diastolic pressure at the $95^{\text {th }}$ percentile for age and sex adjusted for height percentile $25-28$, was detected in $97(7.7 \%)$ children and adolescents.

As for BMI, we identified 172 children and adolescents (13.7\%) on the percentile equal to or above 85 classified as obese $^{29}$. As for TSF, we identified 185 (14.8\%) children and adolescents on the percentile equal to or above 85 (obese patients $)^{29}$. WC on the percentile above 75 identified 117 $(9.3 \%)$ young people with obesity ${ }^{30}$.

The prevalence of HBP in young people with TSF, high $\mathrm{BMI}$ and $\mathrm{WC}$, considered in isolation against those with normal values of these parameters was $16.8 \%, 17.4 \%$ and $19.7 \%$, respectively.

Using the three methods, 92/1,253 juveniles presented obesity simultaneously by BMI $(53.5 \%$ of those with high $\mathrm{BMI})$, excess body fat $(49.7 \%$ from those with high TSF) and abdominal obesity (78.6\% of those with high WC). The prevalence of HBP in this group was $21.7 \%$ (20/92).

Table 1 - Average, standard deviation, median, maximum and minimum of numerical variables studied

\begin{tabular}{lccccc}
\hline & Average & Deviation & Median & Maximum & Minimum \\
\hline $\begin{array}{l}\text { BMl } \\
\left(\mathrm{kg} / \mathrm{m}^{2}\right)\end{array}$ & 18,8 & 3,7 & 18,2 & 41,6 & 12,8 \\
\hline $\begin{array}{l}\mathrm{TSF} \\
(\mathrm{mm})\end{array}$ & 13,6 & 6,3 & 12,2 & 38,2 & 4,0 \\
\hline $\begin{array}{l}\mathrm{WC} \\
(\mathrm{cm})\end{array}$ & 64,8 & 8,9 & 64 & 115 & 43 \\
\hline $\begin{array}{l}\mathrm{SBP} \\
(\mathrm{mmHg})\end{array}$ & 104 & 16,6 & 103 & 178 & 65 \\
\hline $\begin{array}{l}\mathrm{DBP} \\
(\mathrm{mmHg})\end{array}$ & 64 & 11,7 & 64 & 113 & 40 \\
\hline
\end{tabular}




\section{Original Article}

High BMI and TSF were simultaneously present in 37/1,253 students, BMI and WC in 14/1,253, and TSF and WC 4/1,253. BMI, TSF and WC alone were present, respectively, in 29, 52 and 7/1,253 patients investigated. Together or separately, the three parameters identified excess body fat in 235/1,253 people. In this group, the prevalence of HBP was $16.6 \%$.

Using BMI as a reference in the diagnosis of obesity ${ }^{31}$, TSF and WC had, respectively, sensitivity of $75 \%$ and $61 \%$ and specificity of $95 \%$ and $99 \%$.

For young people with HBP, 20/97 (20.6\%) had high BMI, TSF and WC; 1 presented high WC and BMI, 5 had high BMI and TSF, 2 with high WC, 6 with high TSF and high BMI. Thus, HBP in $38 / 97$ (39.2\%) young people can be related to overweight and/or body fat.

The association analysis showed significance $\left({ }^{*} p<\right.$ 0.0001 ) between obesity diagnosed by three anthropometric parameters used, and high blood pressure, as shown in Table 2. The same table shows a significant association between WC and BMI $\left({ }^{*} p<0.0001\right)$, WC and TSF $(* p<0.0001)$ and BMI and TSF $(* p<0.0001)$.

A strong correlation between BMI and TSF and between $\mathrm{BMI}$ and $\mathrm{WC}$ was found; there is a moderate correlation between WC and TSF (* $p<0.01)$. Systolic blood pressure (SBP) showed strong correlation with BMI and WC $\left({ }^{*} \mathrm{p}<\right.$ $0.01)$, and weak correlation with TSF $\left({ }^{*} p<0.05\right)$. Diastolic blood pressure (DBP) presented a weak correlation with BMI, WC $\left({ }^{*} p<0.01\right)$ and TSF $(* p<0.05)$. These results are presented in Table 3.

\section{Discussion}

The recognition that the presence and severity of atherosclerotic lesions are positively and significantly linked with cardiovascular risk factors present in childhood and adolescence ${ }^{2,31,32}$ and that such lesions are more often found from the age of $15^{26}$ it is important to conduct studies showing the prevalence, association and correlation of these factors in populations, as the case of this study. This study found the adverse impact of excess body fat (present in the sample in $13.7 \%$, according to $\mathrm{BMI}$, and $14.8 \%$, according to TSF) and the central deposition of fat (9.3\%), high blood pressure (7.7\%) of children and adolescents in the city of Maceió, through the statistical significance obtained in association analyses and correlations made.

BMI, TSF and WC are adiposity measures commonly used in clinical and epidemiological studies ${ }^{29,30,33}$. Although this study mentions the limitations in using the TSF (due to the possibility of large intra and inter-observer variation and cost of equipment), the World Health Organization directs its use to the diagnosis of obesity in children and adolescents, provided that the measure is used by a professional with specific training, as the case of this research ${ }^{34}$. In our study, we observed a significant association and correlation of BMI (according to some authors, it identifies excess weight, but not necessarily excess fat), TSF (a marker of excess body fat) and WC (marker of central deposition of excess body fat) among themselves and with blood pressure. Strong correlations between $\mathrm{BMI}$ and $\mathrm{TSF}^{20,29}$ and between BMI and WC have been described ${ }^{22,23}$, supporting the findings of this study with respect to these variables.

Despite the strong correlation between the three anthropometric methods, they identified, simultaneously, in this study, the presence of obesity in $50 \%$ of the obese sample. The differences between the methods are expected and reflect

Table 3 - Correlation coefficients between numerical variables of the study

\begin{tabular}{llcc}
\hline & $\begin{array}{c}\text { Body } \\
\text { mass } \\
\text { index }\end{array}$ & $\begin{array}{c}\text { Triceps } \\
\text { skinfold } \\
\text { thickness }\end{array}$ & $\begin{array}{c}\text { Waist } \\
\text { circumference }\end{array}$ \\
\hline $\begin{array}{l}\text { Systolic blood } \\
\text { pressure }\end{array}$ & ${ }^{* *} r=0.43$ & ${ }^{*} r=0.25$ & ${ }^{* *} r=0.44$ \\
\hline $\begin{array}{l}\text { Diastolic blood } \\
\text { pressure }\end{array}$ & ${ }^{* *} r=0.37$ & ${ }^{*} r=0.24$ & ${ }^{*} r=0.36$ \\
\hline $\begin{array}{l}\text { Triceps skinfold } \\
\text { thickness }\end{array}$ & ${ }^{* *} r=0.77$ & $r=1.0$ & ${ }^{* *} r=0.64$ \\
\hline $\begin{array}{l}\text { Waist circumference } \\
{ }^{* *} r=0.87\end{array}$ & ${ }^{* *} r=0.64$ & $r=1.0$ \\
\hline${ }^{*} p<0.05 ;{ }^{* *} p<0.01$. & & &
\end{tabular}

Table 2 - Analysis of association between the variables of this study

\begin{tabular}{|c|c|c|c|c|}
\hline & & $\mathrm{BMI} \geq$ percentile 85 & TSF $\geq$ percentile 85 & WC > percentile 75 \\
\hline & $\mathrm{N}(\%)$ & $172(13.7)$ & $185(14.8)$ & $117(9.3)$ \\
\hline \multicolumn{5}{|l|}{ HBP } \\
\hline Present & $97(7.7)$ & $30^{*}$ & $31^{*}$ & $23^{*}$ \\
\hline Absent & $1.156(92.3)$ & 142 & 154 & 94 \\
\hline WC & $\mathrm{N}(\%)$ & & & \\
\hline$>$ percentile 75 & $117(9.3)$ & $106^{*}$ & $96^{*}$ & \\
\hline$\leq$ percentile 75 & $1,136(90.7)$ & 66 & 89 & \\
\hline \multicolumn{5}{|l|}{ TSF } \\
\hline$\geq$ percentile 85 & $185(14.8)$ & $129^{*}$ & & \\
\hline$<$ percentile 85 & $1,068(85.2)$ & 43 & & \\
\hline
\end{tabular}


the individual characteristics of body fat distribution, but show that in clinical practice, at least two of these parameters will be probably necessary to expand the diagnostic scope of obesity. In this respect, when we use BMI as the standard method for diagnosing obesity ${ }^{34}$, TSF and WC exhibited a high diagnostic specificity in this study. Thus, we can emphasize, as in other studies, that the investigation of obesity in children and adolescents requires the use of BMI associated with another anthropometric method to identify children who present a greater risk of obesity and its consequences.

From the point of view of population, the impact of excess weight or body fat, measured by BMI, high blood pressure in childhood has been well demonstrated by Muntner et $\mathrm{al}^{33}$, who compared pressure data and IMC in 3,496 juveniles aged 8 to 17, assessed in 1988-1994 (NHANES III), with 2086 people of the same age group, assessed in 1999-2000 (NHANES 1999-2000). These authors concluded that there was an increase in blood pressure in the last decade and that this outcome can be partly attributed to the increasing prevalence of excess body weight, also observed in the same population. In Brazil, several studies have demonstrated similar results. Ribeiro et $\mathrm{al}^{21}$, by assessing 1,450 students aged 6 to 18 have shown that individuals with high BMI are 3.6 and 2.7 times more likely to have high systolic blood pressure (SBP) and diastolic blood pressure (DBP), respectively. Monego and Jardim ${ }^{35}$, by studying 3,169 schoolchildren, found a significant association between overweight and hypertension. Guimarães et $\mathrm{al}^{19}$, by assessing data from blood pressure and BMI of 536 adolescents aged 11 to 18 , concluded that the increased percentage of high SBP and DBP followed an increased BMI and each BMI increase would increase SBP by $1.198 \mathrm{mmHg}$.

Using the TSF, more commonly accepted as a marker of excess body fat, Silva and Lopes ${ }^{20}$, by assessing 1,570 students aged 7 to 12 , identified a significant association between excess body fat and high blood pressure (systolic and diastolic). Ribeiro et $\mathrm{al}^{21}$, using the sum of skin folds (including the TSF), showed demonstrated a greater risk of high blood pressure in those with excess body fat.

As for the WC, accepted as a marker of central deposition (visceral) of fat, Guimarães et $\mathrm{al}^{19}{ }^{19}$, by using the same parameter of this study ${ }^{30}$, concluded that the WC has a strong influence on high blood pressure in adolescents. Rosa et $\mathrm{al}^{23}$, also using the same parameter ${ }^{30}$, evaluated 456 students aged 12 to 17 and demonstrated a significant association between hypertension and high WC.

\section{References}

1. Ministério da Saúde. Saúde Brasil 2006. Uma análise da desigualdade em saúde. Secretaria de Vigilância em Saúde. Brasília (DF); 2006.

2. Raitakari OT, Juonala M, Kahonen M, Taittonen L, Laitinen T, Maki-Torkko N, et al. Coronary risk factors measured in childhood and carotid artery intimamedia thickness in adulthood. JAMA. 2003; 290 (17): 2277-83.

3. Bao W, Threefoot SA, Srinivasan SR, Berenson GS. Essential hypertension predicted by tracking of elevated blood pressure from childhood to adulthood: the Bogalusa Heart Study. Am J Hypertens. 1995; 8 (7): 657-65.
Despite a strong correlation between WC, BMI and other anthropometric parameters, Sarni et $\mathrm{al}^{22}$, by assessing 65 preschool children with mean age of 5.8, failed to establish an association or relationship between hypertension and obesity. These authors explained this result as a function of age and limited sample size, and we agree with such explanation.

As in adults, a combination of factors, such as overactivity of the sympathetic nervous system, insulin resistance and abnormalities in vascular structure and function, seem to contribute to the occurrence of hypertension associated with obesity in children and adolescents ${ }^{36}$.

In children, primary hypertension is important for several reasons. Firstly, because it determines damage in target organs. Left ventricular hypertrophy is the most important clinical evidence of this complication ${ }^{27}$. Secondly because there is a trend over life of the persistence of high blood pressure in childhood and adolescence, which makes this behavior (tracking) one of the main markers of hypertension early in adult life $\mathrm{e}^{3,4,27}$. Finally, because of the frequent association, in the same individual, of high blood pressure with other cardiovascular risk factors ${ }^{17,26,27,36}$, which triggers the early appearance and the rapid development of atherosclerotic lesions ${ }^{37,38}$, which determine the most frequent cause of death in Brazil ${ }^{1}$ and in several other parts of the world.

These are the reasons why it is necessary to encourage studies such as this one. Firstly, to enable that, in Brazil, the magnitude of the problem related to the presence of cardiovascular risk factors for atherosclerotic disease among children be identified. Besides this, to make it possible to expand the number of proposals for early prevention of cardiovascular disease in Brazill ${ }^{26}$.

\section{Potential Conflict of Interest}

No potential conflict of interest relevant to this article was reported.

\section{Sources of Funding}

This study was funded by FAPEAL.

\section{Study Association}

This article is part of the thesis of master submitted by Maria Goretti Barbosa de Souza, from Universidade Federal de Alagoas and Universidade Federal de São Paulo.
4. Lauer RM, Clarke WR. Childhood risk factors for high adult blood pressure: the Muscatine Study. Pediatrics. 1989; 84 (4): 633-41.

5. Lauer RM. Role of family history and family testing in cardiovascular risk assessment. Am J Med. 1999; 107 (2A): 14S-15-S.

6. Munger RG, Prineas RJ, Gomes-Marin O. Persistent elevation of blood pressure among children with a family history of hypertension: the Minneapolis Children's Blood Pressure Study. J Hypertens. 1998; 6: 647-53.

7. Brandão AP, Brandão AA, Araújo EMM. The significance of physical 


\section{Original Article}

development on blood pressure curve of children between 6 and 9 years of age and its relationship with familial aggregation. J Hypertens. 1998; 7 (Suppl l): S37-S39.

8. Berenson GS, Srinivisan SR, Hunter SM, Nicklas TA, Freedman DS, Shear CL, et al. Risk factors in early life as predictors of adult disease: the Bogalusa Heart Study. Am J Med Sci. 1989; 298 (3): 141-51.

9. Dahl LK, Heine M, Tassinari L. High salt content of western's infant diet: possible relationship to hypertension in the adult. Nature. 1963; 198: 1204-5.

10. Grobee DE, Vanhooft IMS, de Man SA. Determinants of blood pressure in the first decades of life. J Cardiovas Pharmacol. 1990; 16 (Suppl 7): S71-S74.

11. Hansen HS, Hyldebrandt N, Nielsen JR. A longitudinal study of blood pressure measured in children at rest and during exercise: preliminary results of The Odense Study. Acta Med Scand. 1986; 714 (Suppl): 153-7.

12. Hofman A, Walter HJ, Conelly PA, Vaughan RD. Blood pressure and physical fitness in children. Hypertension. 1987; 9 (2): 188-91.

13. Rosa AA. Pressão arterial numa população escolar: estudo de sua associação com freqüência cardíaca e principais componentes do tamanho corporal. | Tese ]. Porto Alegre: Universidade do Rio Grande do Sul; 1994.

14. Rosa AA. Ribeiro JP. Hipertensão Arterial na infância e adolescência: fatore determinantes. J Pediatr (Rio J). 1999; 75 (2): 75-82.

15. Gutin B, Basch C, Shea S, Contento I, Delozier M, Rips J, et al. Blood pressure, fitness, and fatness in 5 and 6-year old children. JAMA. 1990; 264 (9): 1123-7.

16. Rocchini AP, Katch V, Anderson J, Hinderliter J, Becque D, Martin M, et al. Blood pressure in obese adolescents: effect of weight loss. Pediatrics. 1988; 82 (1): 16-23.

17. Mark AL, Correia M, Morgan DA, Shaffer RA, Haynes WG. Obesityinduced hypertension: New concepts from the emerging biology of obesity. Hypertension. 1999; 33 (part II): 537-41.
18. Ministério da Saúde. Políticas nacionais para a promoção e proteção da alimentação saudável. Panorama epidemiológico e nutricional do Brasil. Seminário Internacional sobre Rotulagem e Propaganda de Alimentos. Brasília. 2006.

19. Guimarães ICB, Almeida AM, Santos AS, Barbosa DBV, Guimarães AC. Pressão arterial: efeito do índice de massa corporal e da circunferência abdominal em adolescentes. Arq Bras Cardiol. 2008; 90 (6): 293-9.

20. Silva KS, Lopes AS. Excesso de peso, pressão arterial e atividade física no deslocamento à escola. Arq Bras Cardiol. 2008; 91 (2): 93-101.

21. Ribeiro RQC, Lotufo PA, Lamounier JA, Oliveira RG, Soares JF, Botter DA. Fatores adicionais de risco cardiovascular associados ao excesso de peso em crianças e adolescentes: o estudo do coração de Belo Horizonte. Arq Bras Cardiol. 2006; 86 (6): 408-18.

22. Sarni RS, Souza FIS, Schoeps DO, Catherino P, Oliveira MCCP, Pessotti CFX et al. Relação da cintura abdominal com a condição nutricional, perfil lipídico e pressão arterial em pré-escolares de baixo estrato econômico. Arq Bras Cardiol. 2006; 87 (2): 153-8.

23. Rosa MLG, Mesquita ET, Rocha ERR, Fonseca VM. Índice de massa corporal e circunferência da cintura como marcadores de hipertensão arterial em adolescentes. Arq Bras Cardiol. 2007; 88 (5): 573-8.

24. Silva MAM, Rivera IR, Ferraz MRMT, Pinheiro AJT, Carvalho ACC, Alves SW, et al. Prevalência de fatores de risco cardiovascular em crianças e adolescentes da rede de ensino da cidade de Maceió. Arq Bras Cardiol. 2005; 84 (5): 387-92.

25. Mion Jr D, Kohlmann Jr O, Amodeo C, Gomes MAM, Nobre F, Brandão A Sociedade Brasileira de Cardiologia / Sociedade Brasileira de Hipertensão / Sociedade Brasileira de Nefrologia. V Diretrizes brasileiras de hipertensão arterial. [Acesso em 2009 8]. Disponível em: http://bvsms.saude.gov.br/bvs/

26. Giuliano ICB, Caramelli B, Pellanda L, Duncan B, Mattos S, Fonseca FH/ Sociedade Brasileira de Cardiologia. I Diretriz de prevenção da aterosclerose na infância e na adolescência. Arq Bras Cardiol. 2005; 85 (supl 6): 1-36. 